\title{
Roturas e Velados: forças autobiográficas
}

\section{Roturas and Velados: autobiographic forces}

\section{Roturas y Velados: forzas autobiográficas}

$\begin{array}{r}\text { Marta Luiza Strambi }^{1} \\ \hline \text { http://dx.doi.org/10.22409/poiesis.1830.13-32 }\end{array}$

RESUMO: Neste texto apresentam-se duas produções em desenho intituladas Roturas e Velados que realizei tendo como dimensão crítica o reconhecimento de aspectos autobiográficos que os motivaram. Trata-se de desenhos que dimensionam suas relações com a presença, reverberando inquietações de urgência a respeito da vida. Essa dimensão crítica do fazer, em sua materialidade, diz respeito ao pensamento expressivo que deflagra suas inquietações diante das complexidades que compreendem uma produção em arte que, como fenômeno contemporâneo, tem como principal propósito uma entrada para tocar em lugares que um corpo já residiu. A compreensão a respeito da autobiografia nas artes visuais, seja ela em qual modalidade for, pode se situar nos limites entre arte e vida, nos acontecimentos privados, que podem ser suscetíveis de se aclarar para "transbordar" no campo de um real.

PALAVRAS-CHAVE: arte; autobiografia; desenho; subjetividade

\footnotetext{
${ }^{1}$ Marta Luiza Strambi é artista visual e professora do PPGAV-IA-UNICAMP e da Especialização em Artes Visuais, Intermeios e Educação. Membro do Grupo de Pesquisa Estudos Visuais, CNPq/UNICAMP. Doutora e Mestre em Artes, IA-UNICAMP e ECA-USP. Especialista em Educação, FE-UNICAMP. Atua em áreas teórico-práticas da arte com articulações com a área da Educação. E-mail: martastrambi@gmail.com
} 
ABSTRACT: In this text, I present two productions in drawing, entitled Roturas and Velados, which I did with the critical dimension of the recognition of the autobiographical aspects that motivated them. These are designs that dimension their relations with the presence, reverberating urgent concerns about life. This critical dimension of doing, in its materiality, refers to the expressive thinking that deflagrates its concerns about the complexities that comprise a production in art as a contemporary phenomenon, that hás, as its main purpose, an entrance to touch places that a body has already resided. The understanding of autobiography in the visual arts, whatever it may be, may lie within the boundaries between art and life, in private events, which may be liable to be clarified in order to "overflow" in the realm of a real.

KEYWORDS: art; autobiography; drawing; subjectivity

RESUMEN: En este texto se presentan dos producciones en diseño tituladas Roturas y Velados, que realicé teniendo como dimensión crítica el reconocimiento de aspectos autobiográficos que los motivaron. Se trata de dibujos que dimensionan sus relaciones con la presencia, reverberando inquietudes de urgencia acerca de la vida. Esta dimensión crítica del hacer, en su materialidad, se refiere al pensamiento expresivo que deflagra sus inquietudes ante las complejidades que comprenden una producción en arte que, como fenómeno contemporáneo, tiene como principal propósito una entrada para tocar en lugares que un cuerpo ya residió. La comprensión acerca de la autobiografía en las artes visuales, sea ella en cual modalidad, puede situarse en los límites entre arte y vida, en los acontecimientos privados, que pueden ser susceptibles de aclararse para "desbordarse" en el campo de un real.

PALABRAS CLAVE: arte; autobiografía; dibujo; subjetividad

Como citar: STRAMBI, Marta Luiza. Roturas e Velados: forças autobiográficas. Poiésis, Niterói, v. 18, n. 30, p. 13-32, dez. 2017.

doi: http://dx.doi.org/10.22409/poiesis.1830.13-32

Poiésis, Niterói, v. 18, n. 30, dez. 2017. 


\section{Roturas e Velados: forças autobiográficas}

"Roturas e Velados: forças autobiográficas" considera os aspectos autobiográficos de duas produções em desenho que realizei, intituladas Roturas e Velados, como dimensão crítica de uma arte contemporânea em questão. Desenhos que dimensionam suas relações, reverberando inquietações de urgência a respeito da vida. Essa dimensão crítica diz respeito ao início de um pensamento que deflagra inquietações diante das complexidades que compreendem uma produção de arte como fenômeno contemporâneo, e que tem como principal propósito uma entrada para tocar em lugares que um corpo já residiu.

Essa série de desenhos, feitos com tinta acrílica sobre papel sob o título Roturas, sem descuidar de sua dimensão estética, integrou o processo de elaboração da instalação "Campo de Forças", discutida anteriormente no $25^{\circ}$. Encontro Nacional da ANPAP (Porto Alegre, em 2016), também teve os processos autobiográficos como base. 
A compreensão a respeito da autobiografia nas artes visuais, seja ela em qual modalidade for, pode se situar nos limites entre arte e vida, nos acontecimentos privados que podem ser suscetíveis de se aclarar para "transbordar" no campo de um real. Um trabalho plástico autobiográfico pode estar na compreensão dos limites do território entre a ficção e uma dada realidade, ou na sua contramão, na qual um contém o outro e vice-versa; contudo, existe aqui uma friç̧ão dos campos em que ambos permanecem inseparáveis. 0 processo dialético "[...] de diálogo e de contaminação com o outro [...]", é o lugar onde pode constituir singularidades, "[...] singularidade e potência lastreadas em sua natureza crítica". (OLIVEIRA; STRAMBI; FARINA, 2017)

Uma autobiografia, como citado em Autobiografía intelectual, "[...] é antes todo um relato de uma vida; como toda obra narrativa é seletiva e, enquanto tal, inevitavelmente descontínua." (RICOUER, 2007, p. 13, tradução nossa). Muitas vezes usamos na arte situações de abandono ou de distanciamento de determinadas passagens da vida; ainda assim, ali se percebe as marcas do artista, colocando-se plenamente, singularizando algo que ele vive ou viveu, pois há aspectos autobiográficos que se basearam em sua identidade sem que seu trabalho fosse um caderno ou um diário do cotidiano.

Para Leonor Arfuch, a "[...] reconfiguração da subjetividade contemporânea [...]" deve considerar a "[...] transformação dos espaços público e privado a nível mundial [...]", isso porque esses espaços Ihes são "indissociáveis", e "[...] aparecem em constante flutuação, submetidos a uma alta interatividade midiática e política, em que parece se desenhar um rumo comum, para além de diferenças e particularismos". Estamos, segundo a autora, em um "momento de aceleração radical" no qual as "lógicas maquinais", que estão "impregnadas nestes processos", operam "em detrimento da qualidade dos sujeitos". A partir disso, a autora considera que a "tendência à privacidade, na insistência do vivencial, do dado singular que se opõe à lei do número, "temos" um ponto de inflexão" que "há mais de dois séculos" está implicado no "despontar da voz autobiográfica". (ARFUCH, 2010, p. 339)

Poiésis, Niterói, v. 18, n. 30, dez. 2017. 
Neste sentido, a "voz autobiográfica" pode ser considerada como um ato de sobrevivência e, também, de resistência diante destes processos culturais que nos submetem às lógicas da homogeneização e do mecanicismo.

Ainda segundo Arfuch, as implicações dessa virada do sujeito contemporâneo para uma "minúcia da subjetividade" ou da "subjetividade no lugar dos sujeitos", poderia tratar-se de um gesto compensatório diante de uma fratura,

[...] dos sujeitos coletivos e dos ideais do universalismo, da queda das utopias sociais, desses "grandes relatos", cuja morte e ressurreição agitaram o debate modernidade/pós-modernidade na década de 1980. Mas esse recolhimento no privado - a vida e a realização pessoal como o maior bem de cada indivíduo -, que reencontra de certo modo seus tons primigênios - aquele "refúgio" da intimidade, essencial no processo civilizador -, não deve necessariamente ser visto como desequilíbrio, abandono do mítico espaço público burguês de racionalidade e fiscalização e, consequentemente, renúncia a toda ação transcendente. Tratar-se-á de perdas e, também, de chances, mutações, reacomodações, combates pela hegemonia em que o uno dá lugar ao múltiplo: haverá vériosespaços públicos e privados, submetidos a um devir dialógico, a um constante processo de interpenetração.

É por isso que, ao falar de espascobiogácico- um singular habitado pela pluralidade -, situamos-nos precisamente nesse umbral de visibilidade indecidível entre público e privado que já mostrara seu caráter paradoxal nos alvores da modernidade: um espaço entre que clausura a antinomia, revelando a imbricação profunda entre indivíduo e sociedade.

A partir desse horizonte analítico, é possível apreender a circulação narrativa das vidas, comuns e singulares, discernir semelhanças e especificidades, à luz de uma concepção dos gêneros discursivos em acordo com isso. Espaço onde algumas formas são naturalmente incluídas, por tradição ou inovação, e outras tornam duvidosa a aplicação mesma do atributo "biográfico", traçando assim uma fronteira, como sabemos, sempre provisória. (ARFUCH, 2010, p. 339-340)

Isso porque a urgência tange a vida, não há como livrar-nos de uma postura que critica as barganhas, seja pela sobrevivência ou mesmo pela troca de favores em que o dinheiro talvez valha mais que um simples gesto de amor. O que fazer com essa carga de obstácu- 
los que enfrentamos, se não partir para um trabalho plástico de intervenção crítica, para opor-nos, talvez, a essa paisagem de casos:

[...] de encontros e de contaminações [...], dos [...] debates em torno de questões que circundam a afirmação do sujeito, [...] do artista e do outro, [...] que afirmam uma urgência cujo enfrentamento não pode ser postergado. (OLIVEIRA; STRAMB|; FARINA, 2017)

\section{Des-limites}

"Roturas e Velados: forças autobiográficas", título deste texto, talvez possa originar uma narrativa ou uma síntese como base, já que podemos analisar as relações entre os conteúdos expressos plasticamente, como nos desenhos a seguir, e sua relação com a realidade vivenciada pelo indivíduo. Parte deste artigo veio como uma protrusão, rompendo a intenção da escritura, como um furacão que incide e varre tudo, exceto o sentimento melancólico das semanas.

Irrompendo em forma de coração, se vê fissuras e incisões, cortes breves que escapam por entre formas sob os títulos "Sob Fenda" e "Exposto" (Figs. 1 e 2).

Mais que uma compreensão, podemos decifrar esses desenhos tocando nas narrativas que os acompanham, narrativas que se vão contando sob sentimentos, sobre as passagens da vida, sensações e eventos como acontecimentos, seriam signos que denotam friç̧ões, em que uma parte se confronta à outra, e que pode revelar uma parte da pessoa que viveu e se incidiu por isso, síntese de um momento refletido como instalação em que os desenhos entrecruzam a arte e a realidade vivenciada.

Os conteúdos expressos nas figuras (Figs. 1, 2, 3, 4), analisados sob as relações com a realidade por mim vivenciada, dizem respeito a um sentimento de medo e, ao mesmo tempo, de desafio a algo que não se quer como forma, mas que se deita sobre o papel. Tomada pelo sentimento, as conformações foram acontecendo; o íntimo sobressaía,

Poiésis, Niterói, v. 18, n. 30, dez. 2017. 


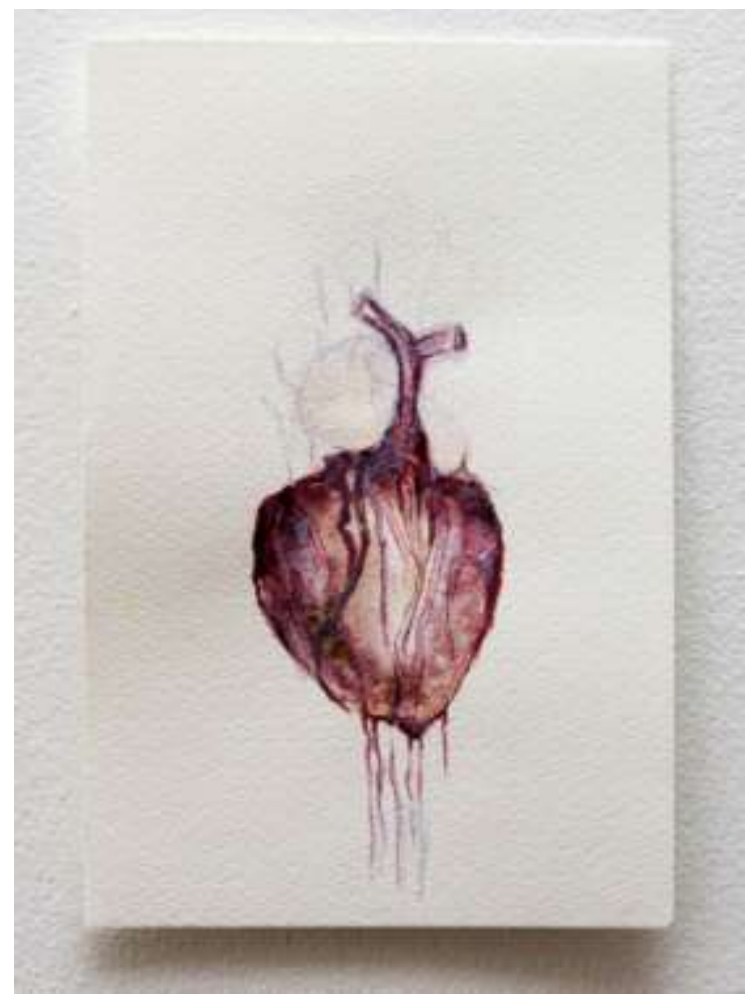

Fig. 1 - Marta Strambi, Sob Fenda, 2016.

acrílica sobre papel, $24 \times 18 \mathrm{~cm}$

(Fonte: Arquivo pessoal da artista) 


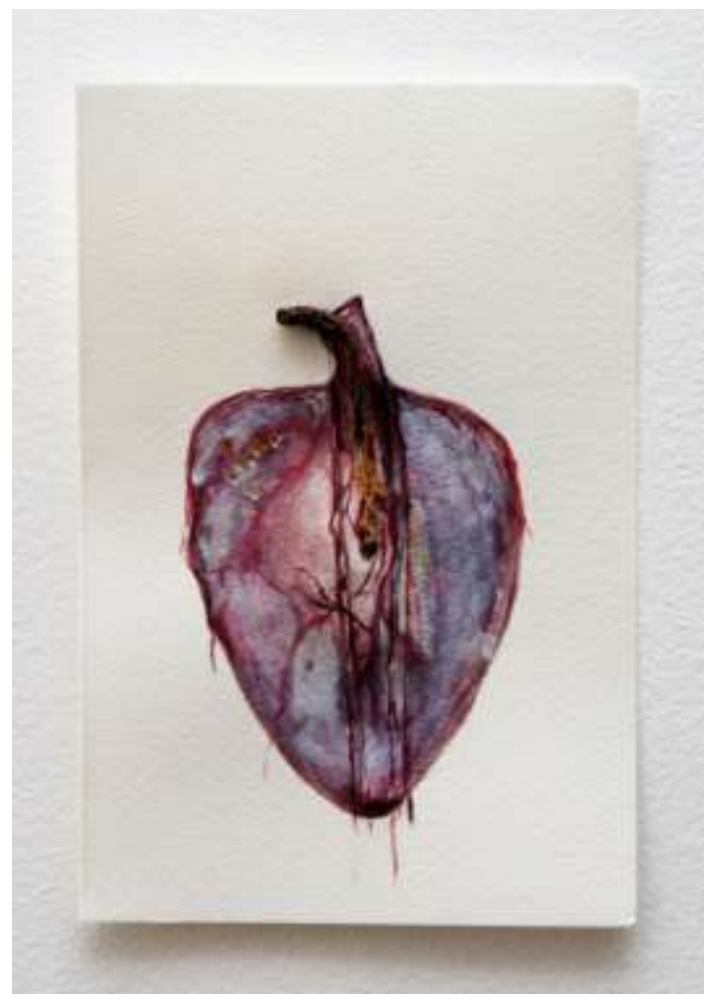

Fig. 2 - Marta Strambi, Exposto, 2016.

acrílica sobre papel, $24 \times 18 \mathrm{~cm}$

(Fonte: Arquivo pessoal da artista)

Poiésis, Niterói, v. 18, n. 30, dez. 2017. 
exteriorizando essas formas de coração, mesmo que as sombras esmaecidas fizessem o contraponto com as duras marcas da tinta sobre o papel.

Com fluídos, ou com escorridos da tinta, todos eles foram sendo elaborados sob esse fulgor do medo, da busca, da identidade, do exílio e da sensibilidade, e foram sendo absorvidos pelos agregados pedaços de guardanapos do enxugar da tinta e mesmo das gotas que escorriam. Sobrepostos, esses pedaços formavam relevos sobre essa produção de "Roturas" (Figs. 3 e 4).

Com essas experimentações, iniciei a criação dos desenhos que fizeram parte da instalação "Campo de Forças" (Figs. de 5, 6, 7, 8, 9 e 10), tratada no meu pós-doutoramento junto ao Instituto Politécnico do Porto (IPP/ESE), na cidade do Porto, em Portugal.

\section{Ceguidades}

Em sequência à experimentação dos desenhos, apresento a "série Velados": Bate I e II (Figs. 5 e 6), fruto daquela produção anterior "Rotunda". Resolvi que fariam parte da instalação geral, então decalcados e com conteúdos expressos, resultado de vivências de sentimentos temerosos e de provocação, dezenove (19) desenhos que se depositavam descorados, pálidos e deficientes. E como se não bastasse, foram cobertos com saquinhos usados de chás, resquícios de uma noite mal dormida, de uma preocupação demoníaca com os hormônios e medicamentos. Eles fizeram o papel de cobertura, de velatura, dos ofuscados e encobertos, desenhos escondidos por papéis.

O que move o artista a criar pode, então, ser sua história e sua vivência, matérias para a criação, entrecruzamentos do devaneio com a realidade exterior; para tanto, ele (ou ela) pode relatar suas experiências, fornecendo elementos próprios e pessoais, estabelecendo um "pacto fantasmático" (LEJEUNE, 2008) com o espectador. 


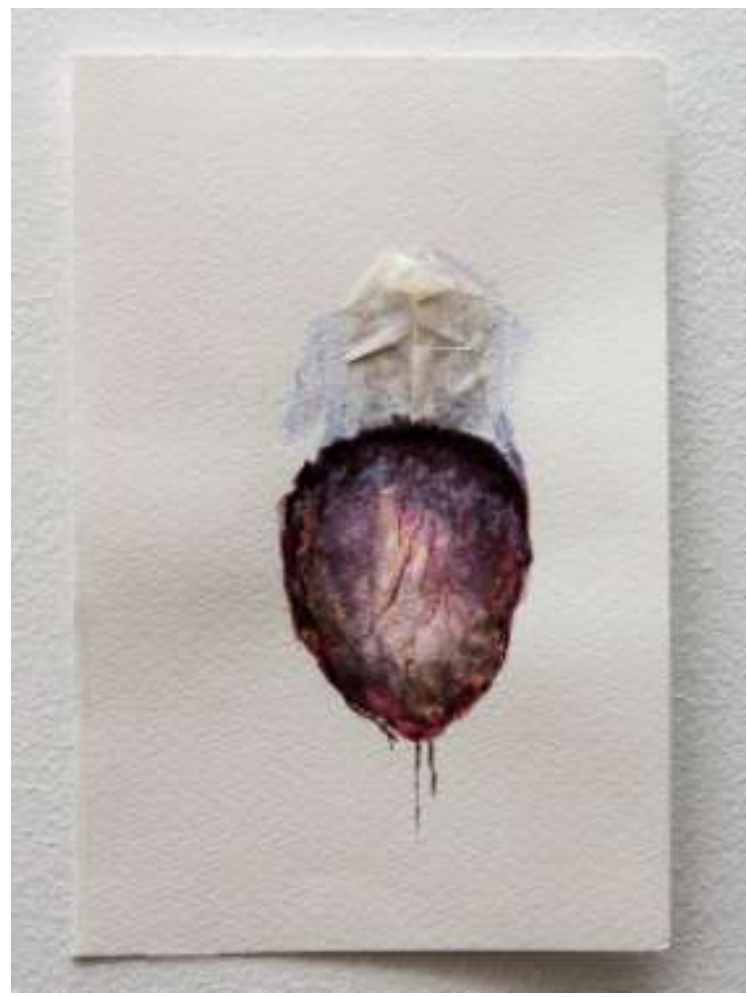

Fig. 3 - Marta Strambi, Sob Lacuna, 2016.

acrílica sobre papel, $24 \times 18 \mathrm{~cm}$

(Fonte: Arquivo pessoal da artista)

Poiésis, Niterói, v. 18, n. 30, dez. 2017. 


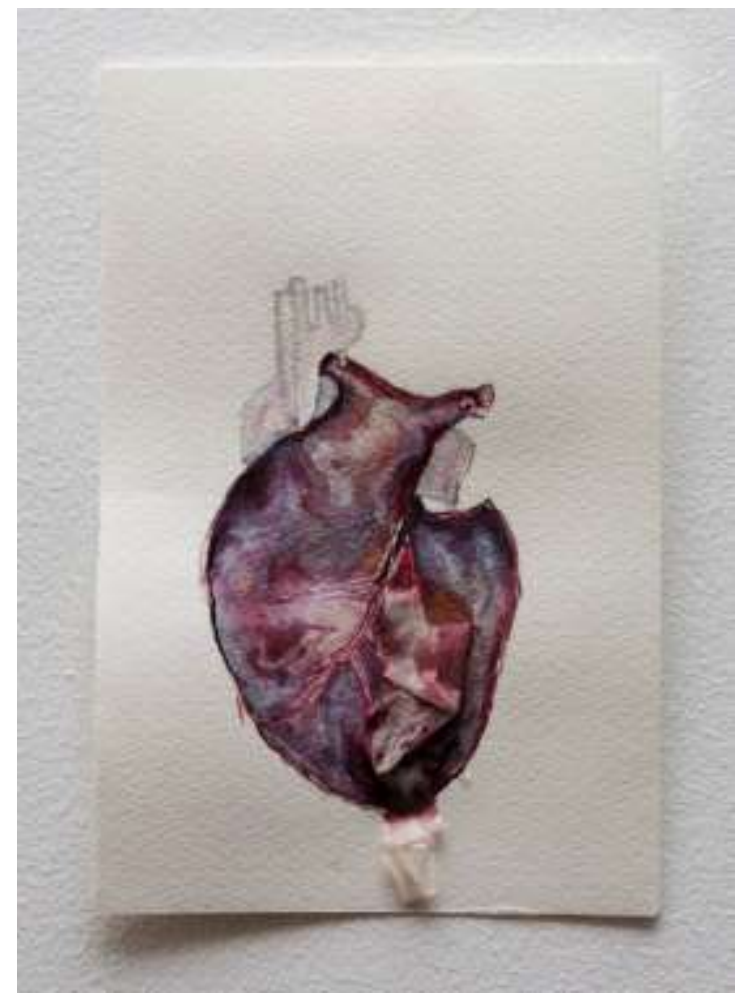

Fig. 4 - Marta Strambi, Filtro, 2016.

acrílica sobre papel, $24 \times 18 \mathrm{~cm}$

(Fonte: Arquivo pessoal da artista) 

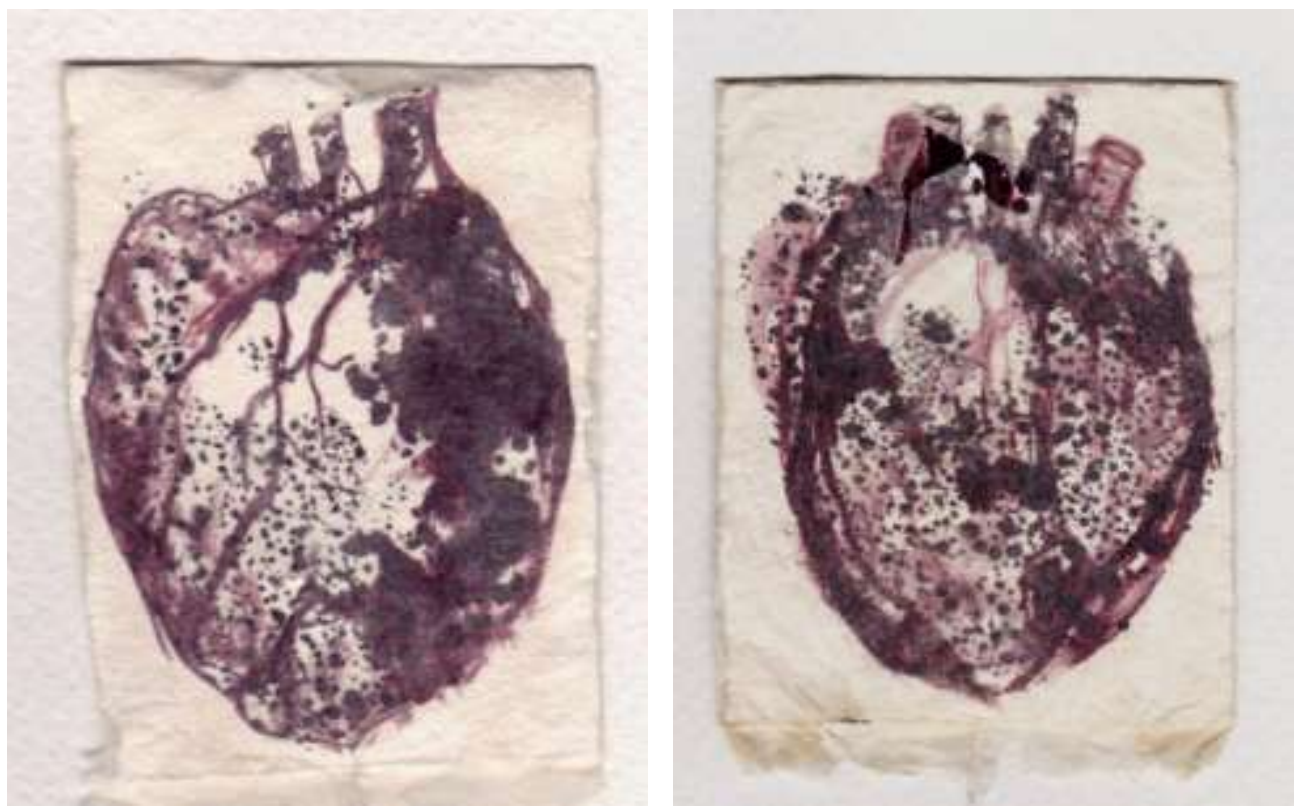

Figs. 5 e 6 - Marta Strambi, Série Velados, Bate I e II, 2016.

decalque em acrílica sobre papel, $5 \times 8 \mathrm{~cm}$

(Fonte: Arquivo pessoal da artista)

Poiésis, Niterói, v. 18, n. 30, dez. 2017. 
Philippe Lejeune quis dizer que o "pacto fantasmático", em uma autobiografia, é a capacidade de perceber, dentro da ficção, elementos reveladores do autor. O espectador passa "[...] a gostar de adivinhar a presença do autor (de seu inconsciente) [...], de tal modo que [...] os pactos fantasmáticos criaram novos hábitos de leitura". (LEJEUNE, 2008, p. 46) Consequentemente, a mesma coisa acontece com os trabalhos visuais. A própria história do artista entra como objeto de sua arte.

A fantasmática, no caso de minhas produções, é um desejo de oferecer uma verdade aos outros ou, então, uma aclamação pelo alerta à vida, ao perigo que se deve ter com aspectos políticos, dogmáticos e ideológicos. É uma ação de expurgo que tem seus efeitos reais.

Como se pode ainda, no século da psicanálise, acreditar que o sujeito seja capaz de dizer a verdade sobre si mesmo?

A promessa de dizer a verdade, a distinção entre verdade e mentira constituem a base de todas as relações sociais. Certamente é impossível atingir a verdade, em particular a verdade de uma vida humana, mas o desejo de alcançá-la define um campo discursivo e atos de conhecimento, um certo tipo de relações humanas que nada têm de ilusório. (LEJEUNE, 2008, p. 103-104)

O território do meu trabalho é o contextual; enfrento questões da autobiografia, do corpo em desalinho e da fragilidade do ser contemporâneo, assuntos que se estabelecem no eixo de minha poética. Considero que minha produção apresenta uma dimensão autobiográfica, isto é, meus projetos partem de experiências/vivências mais íntimas ou dizem respeito a realidades mais gerais que acabam formulando algumas críticas. A memória faz parte dos assuntos tratados; não faço uma projeção de valor sobre eles, mas simplesmente os entendo como uma necessidade, ou seja, uma extensão da vida, uma verdade em si e um jogo poético.

Procuro, nas instalações e ambientações, incorporar e dialogar com o espaço, relacionando-o ao outro, e esses desenhos entram junto, talvez fazendo a parte do "coração", ou seja, dos sentimentos que os envolvem. 
A ideia os constrói; o espaço é um elemento que faz parte das obras e, em geral, faço uma acomodação para o que vou expor. O trabalho acaba tomando parte do espaço como instalação. Tenho, ainda, a necessidade que as pessoas adentrem o trabalho e, por isso, venho inserindo os $\mathrm{mp} 3 \mathrm{e} \mathrm{mp4}$, dando acesso às pessoas para participar e investigar a obra. Esse espaço se esquematiza primeiro dentro de mim, antes de estar no mundo; depois, com experimentos ou maquetes, ele se projeta à luz do improviso que muito prezo e o deixo acontecer através das surpresas ou com elas, incorporando seus sentidos. Já inicio uma criação guardando materiais do meu cotidiano, acumulando do meu dia a dia o que consumo para dar um propósito à "descartagem" que lanço para o mundo, para, enquanto arte, poder dar sentido a eles e ressignificá-los, pois precisam tomar voz no momento; é como um embate entre matéria e materialidade.

Além de serem trabalhados, esses materiais são a chave que escapa da tranquilidade de seguir livre com a vida porque enunciam o que estou vivendo.

Contudo, algumas vezes essa materialidade pode ser um som, que tenho guardado na cabeça, alguma palavra mal focada, ou frases fortes que me ficaram, ou até um acontecimento ou evento que me provocou. Com isso, vou compondo, reunindo essas partes como um todo. Não tenho limites técnicos, procuro me relacionar com todos os meios à disposição e com consequência para a ideia que pretendo apresentar.

O desenho é uma forma de expressão; em cada gesto e energia nele dispendida há uma sentença, uma revelação. Quando feito repetidamente ou previamente pode perder sua vivacidade e expressividade. Ele também deve ser um corpo, uma parte desse todo que a ideia contém.

Não faço nenhuma pesquisa visual anterior; o trabalho vem de "dentro", de minhas vivências. Depois sim, as pesquisas vão acontecendo e preenchendo algum vazio que talvez ainda existia. Elas são mais conceituais, teóricas e seguem sempre por analogia com algum assunto que o trabalho pede ou suplica. A pesquisa acaba dando corpo para alguma escrita, mas estou disposta a trabalhar com minha problemática. O meu próximo trabalho

Poiésis, Niterói, v. 18, n. 30, dez. 2017. 
poderá ser sobre um acontecimento anterior ou, então, algo que me mova à ocasião, vistos sempre como uma crítica. Meus primeiros pensamentos vêm de um reflexo vivido, que altero em forma de arte. Depois tudo entra em jogo e pode se misturar com frases e conceitos a serem trabalhados. O desenho nunca é autônomo, ele também faz parte dessa aposta.

A experimentação é a chave; agora ela está mais dimensionada no meu trabalho, direcionada para se completar. As formas, matérias, formatos e elementos integram o todo da ideia, eles nunca vêm separadamente, e assim continuam até que o trabalho se concretize. A experimentação é como uma liberdade que devemos ter. Ainda assim, gosto de desenhar, gosto de bons papéis, mas não descarto os papéis precários, as gambiarras que me atraem muito e acabam fazendo parte de alguma instalação ou outra ambientação. Meu método parte desde as coisas que vivo, de minha vivência; vou guardando os materiais do dia a dia com os quais me relaciono, até compor uma instalação ou esses desenhos, ou algo parecido. No percurso introduzo desenhos, coisas e sons que me tocam. Geralmente o trabalho vem acompanhado de alguma performance proposta, que vem acontecendo desde a montagem, gravação e fotografias, com a participação das pessoas no trabalho no dia do vernissage.

Não devemos tentar evitar um problema que nos atormenta, nos aborrece ou nos angustia e tratá-lo como obstáculo; enfrentá-lo já é em si parte de sua dissolução. Assim, as obras autobiográficas podem refletir totalmente ou com parcimônia as experiências do sujeito na vida, sejam elas obstáculos, preocupações ou mesmo medo. A presença de si nas obras lança um olhar com finalidades precípuas de se formar ou de se autodepurar, assim como Michel Foucault nos aponta nos textos hupomnêmata ${ }^{1}$ e mesmo nas correspondências em forma de cartas. Elas oferecem tanto para o destinatário quanto ao signatário possibilidades de reflexão, podendo ser entendidas não somente como um decifrarse de si por si, mas "[...] como uma abertura que se dá ao outro sobre si mesmo." (FOUCAULT, 2006, p. 157). 

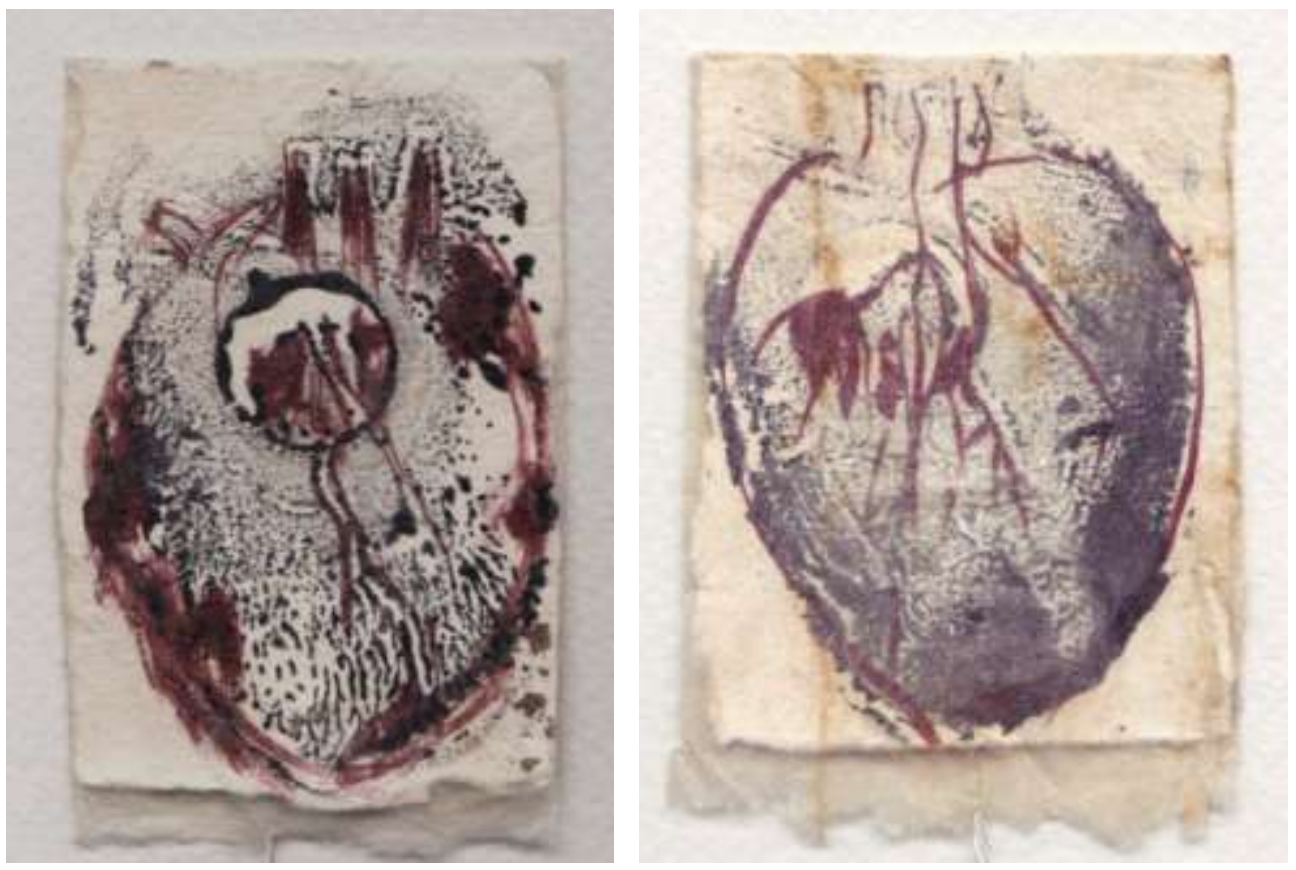

Figs. 7 e 8 - Marta Strambi, Série Velados, Bate III e IV, 2016.

decalque em acrílica sobre papel, $5 \times 8 \mathrm{~cm}$

(Fonte: Arquivo pessoal da artista)

Poiésis, Niterói, v. 18, n. 30, dez. 2017. 

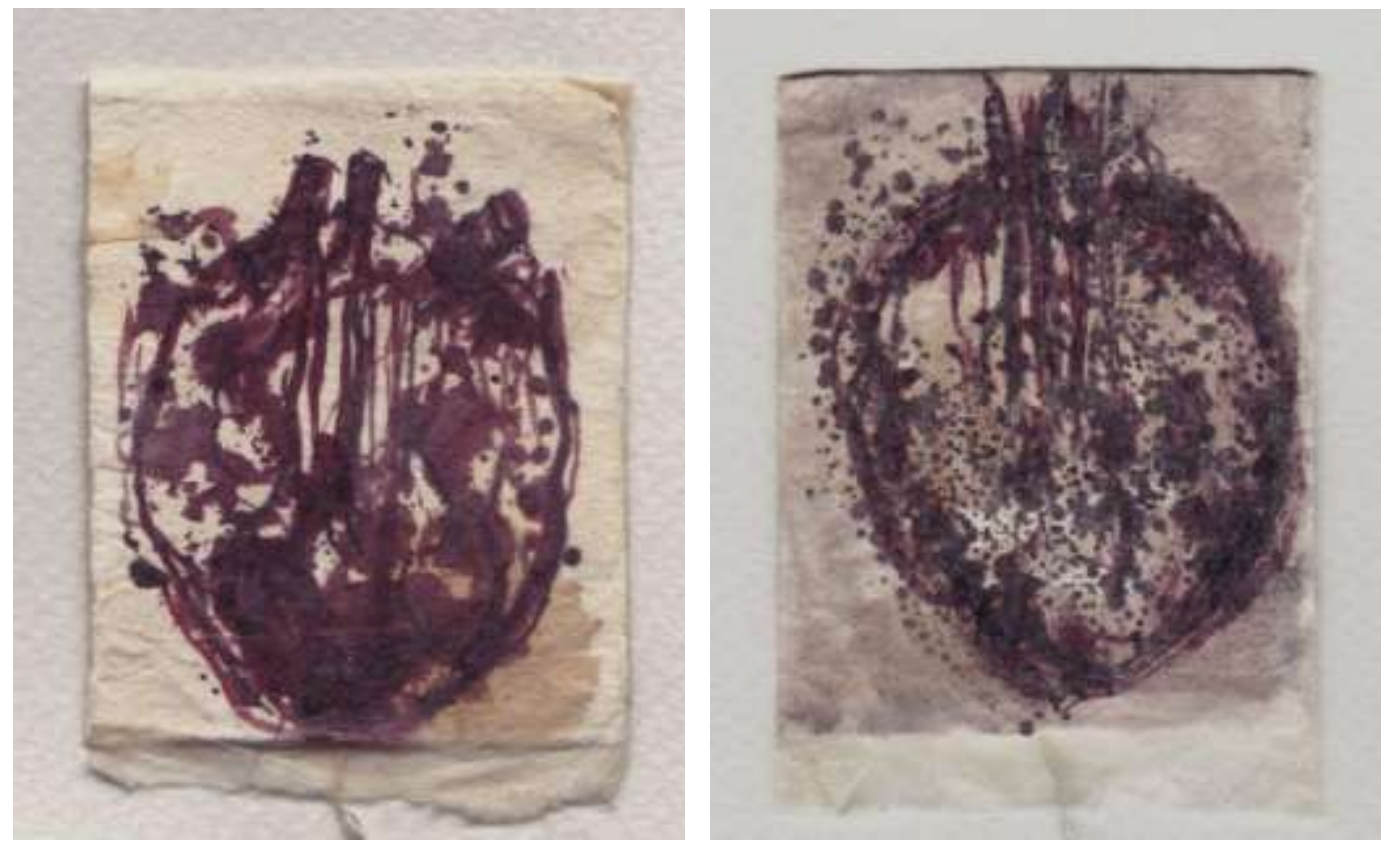

Figs. 9 e 10 - Marta Strambi, Série Velados, Bate V e VI, 2016.

decalque em acrílica sobre papel, $5 \times 8 \mathrm{~cm}$

(Fonte: Arquivo pessoal da artista) 
Em Santo Agostinho também encontramos um tom autobiográfico em sua obra Livro $X$, em Confissões, redigida em 387-388 d.C., como se fosse um diário no qual ele se arrepende de alguns de seus "pecados". Encontramos seus deleites sobre as artes quando ele escreve a respeito de $O$ prazer do ouvido, $A$ sedução dos olhos, $A$ sedução do perfume, entre outros. Com isso, ele deixa à vista a relação das artes com o dogmatismo da Igreja em seus inícios, demonstrando um comprometimento enclausurado, no qual a percepção e a contemplação das artes e das belezas da vida, se configurava como "pecados".

Quando, às vezes, a música me sensibiliza mais do que as letras que se cantam, confesso com dor que pequei. Neste caso, por castigo, preferiria não ouvir cantar. Eis em que estado me encontro.

Os olhos amam a beleza e a variedade das formas, o brilho e a amenidade das cores [...]. A própria rainha das cores, esta luz que se derrama por tudo o que vemos e por todos os lugares em que me encontro no decorrer do dia, investe contra mim de mil maneiras e acaricia-me, até mesmo quando me ocupo em outra coisa que dela me abstrai. Insinua-se com tal veemência que, se de repente me for arrebatada, procuro-a com vivo desejo. Se se ausenta por muito tempo, a minha al ma cobre-se de tristeza.

[...] também me deixo prender por estas belezas; mas Vós, ó Senhor, libertais-me! (AGOSTINHO, 1996, p. 293-295)

Nesse mesmo livro, Santo Agostinho trata de uma análise sobre a memória dos afetos da alma e a busca pela felicidade; enfim, a obra autobiográfica problematiza "[...] os modos pelos quais a subjetividade" ${ }^{2}$ se constitui, inclusive na arte e por meio dela. Ela vem se fazendo através de novas formas de expressão de si no campo da imagem, se configurando, como um espaço dialógico e em muitos casos intertextual.

Corremos contra o tempo para entendermos e nos posicionar frente a um fenômeno cultural, subjetivo e social que aponta para um limite tênue, e muitas vezes problemático, entre o ético e o estético: trata-se de uma exposição de si sem vínculos com a dimensão do comum e do coletivo, ancorada apenas [...] na arte em si. Ou trata-se de formas de experimentação de si que nos afastam das identidades fechadas e nos colocam frente à dimensão relacional, mutante, inacabada e faltante das subjetividades partilhadas? Com efeito, a inflação ou hipertrofia da subjetividade contemporânea pode ser vista apenas como sinto-

Poiésis, Niterói, v. 18, n. 30, dez. 2017. 
ma do mundo atual, mas pode também resistir a esse mundo, ao interrogar as interseções entre as esferas pública e privada, a história e a memória, o íntimo e o êxtimo, o pessoal e o político. ${ }^{3}$

Em nossa sociedade, o trabalho reprodutivo se tornou a atividade principal; a uniformização e padronização se apresentam nos modos e nos aspectos do ser e da ocupação humana, sendo ao revés, paradoxalmente, a unicidade o que alimenta a certeza do individual e singular. Essa repetição que interfere nessa busca individual, na realidade é ela uma ilusão de um "nós", uma tensão entre utopia e realidade.

Parto da problematização de tais processos para considerar, como experiência sensível, as formas subjetivas de expressão como a autobiografia na arte quando capturamos e problematizamos um conteúdo próprio, deixando-o atravessar por diferentes modos, sejam eles íntimos ou não, como argumento principal de uma produção em arte. Proponho tensionar, através das esferas pública/privada e poética/política, as estruturas do modo de fazer e da disseminação da arte por meio da autobiografia. Viso, com isso, tirar a arte da solidão e romper com mecanismos imperiosos de fincar a arte em um caminho distante e decepá-la da convivência humana.

\section{Notas}

1 Caderno de anotações pessoais dos gregos (cultura filosófica pré-cristã).

${ }^{2}$ Ver em http://www.fafich.ufmg.br/devires/index.php/Devires

${ }^{3}$ Ver em http://www.fafich.ufmg.br/devires/index.php/Devires

\section{Referências}

AGOSTINHO, Santo. Confissões. São Paulo: Nova Cultural, 1996.

ARFUCH, Leonor. "Cronotopías de la intimidad". In ARFUCH, Leonor. Pensar este tiempo, espacios, afectos, pertenencias. Buenos Aires: Paidós, 2005.

ARFUCH, Leonor. O espaço biográfico: dilemas da subjetividade contemporânea. Trad. Paloma Vidal. Rio de Janeiro: EdUERJ, 2010. 
CHEVRIER, Jean-François. Formas Biográficas. Construcción y mitología individual. Madrid: Museu Nacional Centro de Arte Reina Sofia, 2014.

FOUCAULT, Michel. A escrita de si. In FOUCAULT, Michel. Ditos e Escritos V: Ética, Sexualidade e Política. Rio de Janeiro: Forense Universitária, 2006.

FOUCAULT, M. Uma estética da existência. In FOUCAULT, Michel. Ética, Sexualidade, Política. Org. por Manoel Barros da Motta. Rio de Janeiro: Forense-Universitária, 2006.

LEJEUNE, Philippe. O pacto autobiográfico: de Rousseau à internet. Trad. Jovita Maria Gerheim Noronha. Belo Horizonte: Editora da UFMG, 2008.

OLIVEIRA, L.S.; STRAMBI, Marta; FARINA, Mauricius. Simpósio 3: Entre a obra e o mundo: a dimensão crítica da arte. In ANPAP. Anais do $25^{\circ}$ Encontro Nacional da ANPAP. Arte: seus espaços e/em nosso tempo, Porto Alegre, 2016.

OLIVEIRA, L.S.; STRAMBI, Marta; FARINA, Mauricius. Simpósio 11: O Político, O Estético, O Crítico: dimensões da arte e do artista no contemporâneo. In ANPAP. Anais do $26^{\circ}$ Encontro Nacional da ANPAP. Memórias e Inventações, Campinas, 2017.

RICOEUR, Paul. Autobiografía intelectual. Buenos Aires: Nueva Visión, 2007. 